\title{
Simultaneous Liquid Chromatographic Determination of Two Co- Prescribed Anti-Cancer Drugs in Bulk Drug, Dosage Formulations and in Human Serum Using Multivariate Technique: Application to in vitro Drug Interaction
}

\section{Najma Sultana ${ }^{1}$, Saeed Arayne M$^{2}$, Saeeda Nadir Ali and Arman Tabassum²}

${ }^{1}$ Department of Pharmaceutical Chemistry, Faculty of Pharmacy, University of Karachi, Karachi-75270

${ }^{2}$ Department of Chemistry, University of Karachi, Karachi-75270

\begin{abstract}
Present study describes the development and validation of a high-performance liquid chromatographic (HPLC) assay for the simultaneous quantification of atorvastatin and celecoxib in human serum and pharmaceutical formulations. The separation was carried out on Bondapak, $C_{18}(10 \mu \mathrm{m}, 25 \times 0.46 \mathrm{~cm})$ column using mobile phase 80:20 methanol-water of $\mathrm{pH} 3.5$, maintained with o-phosphoric acid. The method was optimized using multivariate technique and detector response was recorded at five different wavelengths. Chromatography was performed at ambient temperature by pumping the mobile phase at a flow rate of $1.0 \mathrm{~mL} \mathrm{~min}^{-1}$. Calibration curves were found to be linear with correlation coefficient greater than 0.998 over the concentration range $2-60$ and $2-70 \mathrm{ng} \mathrm{mL}^{-1}$ with detection limits 0.024 and $0.019 \mathrm{ng} \mathrm{mL}^{-1}$ in bulk drug and 0.04 and $0.01 \mathrm{ng} \mathrm{mL}^{-1}$ in serum at isobestic point. The method was validated for specificity, selectivity, and linearity, accuracy, precision and intermediate precision. The proposed method is valid for the determination of drugs in pharmaceutical formulations without interference of excipients. Recovery values of both drugs were 99.33 to $101.65 \%$. Moreover the in vitro interaction studies of atorvastatin in presence of celecoxib were carried out at physiological temperature $\left(37^{\circ} \mathrm{C}\right)$, simulating stomach environment and the reactions were studied by RP-HPLC.
\end{abstract}

Keywords: Atorvastatin; Celecoxib; Anticancer drugs; HPLC; Multivariate, Drug interaction

\section{Introduction}

Atorvastatin (Figure 1a) belongs to lipid-lowering drug class statins, widely used for the treatment of hypercholesterolemia [1] to reduce total cholesterol, LDL in blood [2], apo-B which is responsible for carrying cholesterol to tissues [3], triglycerides levels [4] and C-reactive protein (CRP) [5] as well as increase HDL levels. Besides, they are potent anti-oxidative [6,7], antitumor [8], anti-inflammatory $[9,10]$, immunomodulator [11,12], anti-malarial [13] and bone forming agents [14]. They also reduce the risk of total prostate cancer as well as more aggressive prostate cancer [15]. Moreover, patients who are taking statins, showed significantly lower pretreatment prostatespecific antigen level, percentage of positive biopsy cores and earlier clinical stage [16].

Celecoxib (Figure 1b) is a non-steroidal anti-inflammatory drug (NSAID), used to treat inflammatory conditions such as rheumatoid arthritis, osteoarthritis and ankylosing spondilytis [17]. NSAIDs are known to relief symptoms of primary dysmenorrhea, fever and also possess mild antiplatelet effect. They are useful in sepsis-induced acute pneumonia [18] and in retarding metastases of mammary carcinoma [19]. Celecoxib may delay or help in preventing progression in prostate cancer patients [20].

Statins are administered together with NSAIDs to hypercholesterolemia patient also suffering from inflammations [21]. Atorvastatin and celecoxib are two widely co-prescribed drugs for clinical treatment of not only such problems but recent in vivo studies have showed that atorvastatin in combination with celecoxib inhibits prostate PC-3 tumors in immunodeficient mice [22], suppresses the incidence and multiplicity of colon adenocarcinoma in the azoxymethane-induced rat colon carcinogenesis model $[23,24]$. The possible mechanisms by which statins and NSAIDs inhibit growth of cancer cell are described by Xiao and Yang [21]. Atorvastatin and celecoxib in combination has a potent inhibitory effect on the progression and growth of androgen-dependent prostate tumors to androgen independence in a xenograft model $[25,26]$, also they have potency to prevent progression of atherosclerosis [27].

A variety of techniques have been reported for the analysis of atorvastatin alone or in combination with other drugs [28-32], similarly different analytical procedures have been reported for the determination of celecoxib [33-35] in bulk drug, human serum and in pharmaceutical formulation. To the best of our knowledge, there is no LC method yet reported for separation and simultaneous analysis of these two drugs in human serum and in pharmaceutical formulation with lowest detection limits.

Chemometrics is the discipline that uses mathematical and statistical methods to extract the relevant information on material systems. Both descriptive and predictive problems, especially in chemistry are untied by applying chemometrics employing core data-

${ }^{*}$ Corresponding author: Saeeda Nadir Ali, Department of Chemistry, University of Karachi, Karachi-75270, E-mail: saeeda_khowaja@hotmail.com

Received January 30, 2013; Accepted March 20, 2013; Published March 25, 2013

Citation: Sultana N, Saeed Arayne M, Nadir Ali S, Tabassum A (2013) Simultaneous Liquid Chromatographic Determination of Two Co-Prescribed AntiCancer Drugs in Bulk Drug, Dosage Formulations and in Human Serum Using Multivariate Technique: Application to in vitro Drug Interaction. Pharmaceut Anal Acta 4: 215. doi:10.4172/2153-2435.1000215

Copyright: @ 2013 Sultana N, et al. This is an open-access article distributed unde the terms of the Creative Commons Attribution License, which permits unrestricted use, distribution, and reproduction in any medium, provided the original author and source are credited. 
Citation: Sultana N, Saeed Arayne M, Nadir Ali S, Tabassum A (2013) Simultaneous Liquid Chromatographic Determination of Two Co-Prescribed Anti-Cancer Drugs in Bulk Drug, Dosage Formulations and in Human Serum Using Multivariate Technique: Application to in vitro Drug Interaction. Pharmaceut Anal Acta 4: 215. doi:10.4172/2153-2435.1000215

Page 2 of 7
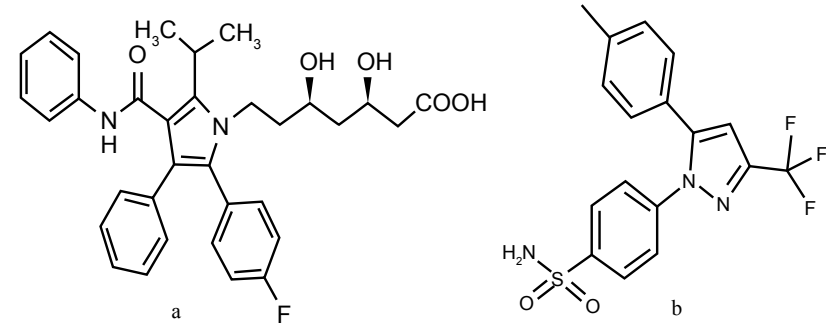

Figure 1: Chemical structure of (a) atorvastatin and (b) celecoxib

analytic disciplines such as multivariate statistics, applied mathematics, and computer science. Evenly, multivariate calibration allows for accurate quantitative analysis in the presence of heavy interference by other analytes. In the present study, multivariate calibration technique has been applied for simultaneous LC determination of atorvastatin and celecoxib in order to minimize the limitations of single data processing. Under the optimized conditions, the proposed technique was successfully applied for the routine analysis of both drugs with high resolution and sensitivity. Mathematically;

$$
\begin{aligned}
& A_{240}=a^{*} C_{x}+k_{1} \\
& A_{245}=b^{*} C_{x}+k_{2} \\
& A_{250}=c^{*} C_{x}+k_{3} \\
& A_{255}=d^{*} C_{x}+k_{4} \\
& A_{260}=e^{\star} C_{x}+k_{5}
\end{aligned}
$$

where, A represents the area under curve of analyte, $\mathrm{C}_{\mathrm{x}}$ is the concentration of analyte, a, b, c, d and e are the slope and $\mathrm{k}_{1} \mathrm{k}_{2} \mathrm{k}_{3}$ $\mathrm{k}_{4}$ and $\mathrm{k}_{5}$ are the intercept of linear regression equation at different wavelengths. The sum of above equations is as follows; which can be rearranged as equation (7) to determine the concentration of analytes.

$$
\begin{aligned}
& \mathrm{A}_{\mathrm{T}}=(\mathrm{a}+\mathrm{b}+\mathrm{c}+\mathrm{d}+\mathrm{e}) \mathrm{C}_{\mathrm{x}}+\mathrm{K}_{\mathrm{T}} \\
& \mathrm{C}_{\mathrm{x}}=\mathrm{A}_{\mathrm{T}}-\mathrm{K}_{\mathrm{T}} /(\mathrm{a}+\mathrm{b}+\mathrm{c}+\mathrm{d}+\mathrm{e})
\end{aligned}
$$

where, $A_{T}$ and $K_{T}$ represents the sum of area and intercepts at different wavelength.

The method was found to be sensitive for the determination of these drugs in human serum and pharmaceutical formulation without interference of excipients. Moreover the in vitro interaction studies were carried out at physiological temperature $\left(37^{\circ} \mathrm{C}\right)$ in different $\mathrm{pH}$ like $\mathrm{pH}$ 4, 6.8 and 9, simulating stomach environment (full stomach and intestinal $\mathrm{pH}$ ) and the reactions were studied by RP-HPLC.

\section{Experimental}

\section{Materials and reagents}

Atorvastatin calcium was a classic gift by Genix Pharma Private Limited and celecoxib was obtained from Getz Pharma. Both raw substances were used as reference standards without any extra purification process. Pharmaceutical formulations named Genovax $(10 \mathrm{mg})$ and Celbexx capsules $(100 \mathrm{mg})$ were purchased from local pharmacy (Karachi). The human serum used for this research was voluntarily donated by a healthy person at Fatmid Foundation Karachi. Analytical grade methanol and 85\% o-phosphoric acid were obtained from Merck, Darmstadt, Germany. Double distilled de-ionized water was used throughout the procedure. All solutions were filtered through $0.45 \mu \mathrm{m}$ filter and degassed by sonicator.

\section{Instruments}

Dissolution equipment manufactured according to B.P 2007 standard with slight modification. Shimadzu 1800 UV-visible spectrophotometer was used for the determination of isosbestic point and individual $\lambda_{\text {max }}$ of analyte. The HPLC system consisted of Shimadzu LC-20-AT HPLC pump, rheodyne manual injector fitted with a $20 \mu \mathrm{L}$ loop and a variable wavelength programmable SPD-20A Shimadzu UV-visible detector. Chromatographic separation was achieved on a Bondapak, $\mathrm{C}_{18}(10 \mu \mathrm{m}, 25 \times 0.46 \mathrm{~cm})$ column. The chromatographic and integrated data were recorded using a CBM-102 communication Bus Module Shimadzu. Data acquisition was performed by Shimadzu Class-GC 10 software (version 2).

\section{Chromatographic conditions}

A mixture of methanol and water $(80: 20 \mathrm{v} / \mathrm{v})$ was used as mobile phase, the $\mathrm{pH}$ of which was adjusted to 3.5 using o-phosphoric acid $(85 \% \mathrm{w} / \mathrm{w})$. The mobile phase used throughout was freshly prepared and was filtered through a millipore vacuum filter system equipped with $0.45 \mu \mathrm{m}$ filter and degassed by a sonicator. Chromatography was performed at ambient temperature by pumping the mobile phase at flow rate of $1.0 \mathrm{~mL} \mathrm{~min}{ }^{-1}$. Column effluent was monitored at five different wavelengths including 240,245, 250, 255 and $260 \mathrm{~nm}$.

\section{Stock standard solutions}

Accurately weighed $10 \mathrm{mg}$ of standard atorvastatin and celecoxib were transferred in to two separate $100 \mathrm{~mL}$ volumetric flasks and volumes were made up with 80:20 methanol-water diluent to bring the final concentration of $100 \mu \mathrm{g} \mathrm{mL}{ }^{-1}$. These solutions were further used for preparation of working solutions of drugs. The stock solutions were prepared once and stored at $4^{\circ} \mathrm{C}$ protected from light.

Buffer of $\mathrm{pH} 4$ was prepared by taking $0.1 \mathrm{M}$ potassium chloride and its $\mathrm{pH}$ was adjusted with $0.1 \mathrm{~N}$ hydrochloric acid. For preparing pH 6.8 buffer, potassium dihydrogen orthophosphate $(0.6 \mathrm{~g})$, disodium hydrogen orthophosphate $(6.4 \mathrm{~g})$ and sodium chloride $(5.85 \mathrm{~g})$ were dissolved in $1000 \mathrm{~mL}$ deionized water and $\mathrm{pH}$ was adjusted with $17 \%$ ammonium hydroxide. $\mathrm{pH} 9$ buffer was prepared by dissolving $17.4 \mathrm{~g}$ of potassium dihydrogen orthophosphate in $800 \mathrm{~mL}$ of deionized water and $\mathrm{pH}$ was adjusted with $17 \%$ ammonium hydroxide.

\section{Analytical procedure}

Aliquots of each solution were accordingly diluted with 80:20 methanol-water diluent to working standard solutions of concentration range 2-60 and 2-70 $\mathrm{ng} \mathrm{mL}^{-1}$ for atorvastatin and celecoxib respectively. $20 \mu \mathrm{L}$ of these solutions were injected into the $\mathrm{LC}$ system $(n=5)$. Before analysis, all the solutions were filtered through a $0.45 \mu \mathrm{m}$ vacuumed filter and degassed by sonicator.

\section{Pharmaceutical preparations}

Ten tablets of Genovax and ten Celbexx capsules were separately powdered and amount equivalent to $10 \mathrm{mg}$ of atorvastatin and 10 $\mathrm{mg}$ of celecoxib were dissolved in mobile phase in separate $100 \mathrm{~mL}$ volumetric flasks. The solutions were subjected to vigorous shaking and then allowed to stand for $1 \mathrm{~h}$ with intermittent sonication for complete extraction of the drug. Both the solutions were then filtered and volume was brought to mark with mobile phase and then treated as above.

\section{Drug serum solution}

The drug serum solution was prepared by adding $1.0 \mathrm{~mL}$ of serum in 
Citation: Sultana N, Saeed Arayne M, Nadir Ali S, Tabassum A (2013) Simultaneous Liquid Chromatographic Determination of Two Co-Prescribed Anti-Cancer Drugs in Bulk Drug, Dosage Formulations and in Human Serum Using Multivariate Technique: Application to in vitro Drug Interaction. Pharmaceut Anal Acta 4: 215. doi:10.4172/2153-2435.1000215

Page 3 of 7

$9 \mathrm{~mL}$ of acetonitrile. The mixture was vortexed for one minute and then centrifuged for 10 minutes at $10,000 \mathrm{rpm}$. The obtained supernatant was filtered by $0.45 \mu \mathrm{m}$ membrane filter. The clear solution obtained was spiked with drug solutions to produce desired concentrations of atorvastatin $\left(4,8\right.$ and $\left.16 \mathrm{ng} \mathrm{mL}^{-1}\right)$ and celecoxib $\left(4,8\right.$ and $\left.16 \mathrm{ng} \mathrm{mL}^{-1}\right)$ in human serum. $20 \mu \mathrm{L}$ of these solutions were injected into the LC system.

\section{Method validation}

The method was validated following the ICH 2006 guidelines by reporting its linearity, limit of detection and quantification as well as precision and recovery of atorvastatin and celecoxib in its formulation and human serum. Also the specificity and selectivity, system suitability and robustness were measured.

The system suitability was evaluated on each day of method validation after equilibrating the HPLC system with initial mobile phase composition, by injecting ten replicates of same standard. The detector response was observed. For specificity studies, chromatograms of pure solvent, reference standards, solution of pharmaceutical formulation and blank and spiked serum sample were recorded and interference due to excipients of tablet and endogenous components of serum were observed. Linearity was evaluated by plotting calibration curve between concentration and peak area for API and serum at five different wavelengths 240,245,250, 255 and $260 \mathrm{~nm}$ at six concentration level for each component and regression characteristics including intercept, slope and correlation coefficient were calculated. Accuracy was determined by calculating the found concentration and percentage of recovery of analytes in pharmaceutical formulation and human serum at all the wavelengths in the concentration range of 2-60 and 2-70 ng $\mathrm{mL}^{-1}$ for atorvastatin and celecoxib respectively. Five replicates at six concentration levels for reference standard and three samples of human serum were analyzed for the determination of precision of the proposed method. It is reported as percent relative standard deviation. The LOD and LOQ were determined at the concentration where signal to noise ratio was three times and ten times to the baseline noise respectively. Some of the chromatographic parameters like $\mathrm{pH}$ and composition of mobile phase, flow rate and wavelength were intentionally varied and the subsequent effect on analytical results was observed.

\section{In vitro interaction studies by RP-HPLC}

$100 \mathrm{~mL}$ stock solution of $100 \mu \mathrm{g} \mathrm{mL} \mathrm{m}^{-1}$ atorvastatin and celecoxib were separately prepared in simulated gastric juice buffers of $\mathrm{pH} 4,6.8$ and 9 individually. Equal volume of each drug solution for each $\mathrm{pH}$ was mixed together in reaction flask to get the final concentration of $50 \mu \mathrm{g} \mathrm{mL} \mathrm{m}^{-1}$. These flasks were kept at water bath at $37^{\circ} \mathrm{C}$ for two hours for interaction with constant stirring. $2 \mathrm{~mL}$ of these solutions were withdrawn at $0 \mathrm{~min}$ and periodically after every $15 \mathrm{~min}$ for $2 \mathrm{~h}$, filtered through $0.45 \mu \mathrm{m}$ membrane filter and analyzed by HPLC employed the proposed method. The volume of dissolution fluid was maintained by adding an equal amount of dissolution fluid withdrawn, which had previously been maintained at the same temperature in the same bath.

\section{Results and Discussion}

UV scan of atorvastatin and celecoxib showed maximum absorbance at 248 and $254 \mathrm{~nm}$ respectively (Figure 2); therefore in order to minimize error and investigate the optimum conditions, a well known multivariate technique is applied for the determination of these drugs in binary mixture which provides significant improvements in precision over methods that are restricted to a small number of wavelengths. The five linear regression functions at wavelengths of 240, 245, 250, 255 and $260 \mathrm{~nm}$ for individual active compounds were calculated by using relationships between the multivariate HPLC data and linearity range. Along with the multivariate analysis, a fixed suitable wavelength of $250 \mathrm{~nm}$, selected from UV spectra of individual drug, was chosen for the liquid chromatographic analysis in API, pharmaceutical formulation and human serum and then method was validated. The representative showing the retention times of 3.08 and $4.34 \mathrm{~min}$ for atorvastatin and celecoxib respectively is given in figure 3. Multivariate calibration technique applied to the pharmaceutical formulations is expressed in table 1 and the precision of method at different wavelengths are given in table 2 . The regression characteristics including slope, intercept, standard error, standard error estimate and correlation coefficient for both drugs at different wavelengths were determined by plotting calibration curves between concentrations of drug against peak area. Table 3 represents the regression characteristics and detection and quantitation limits at each wavelength. Multivariate chromatogram of atorvastatin and celecoxib is represented in figure 4.

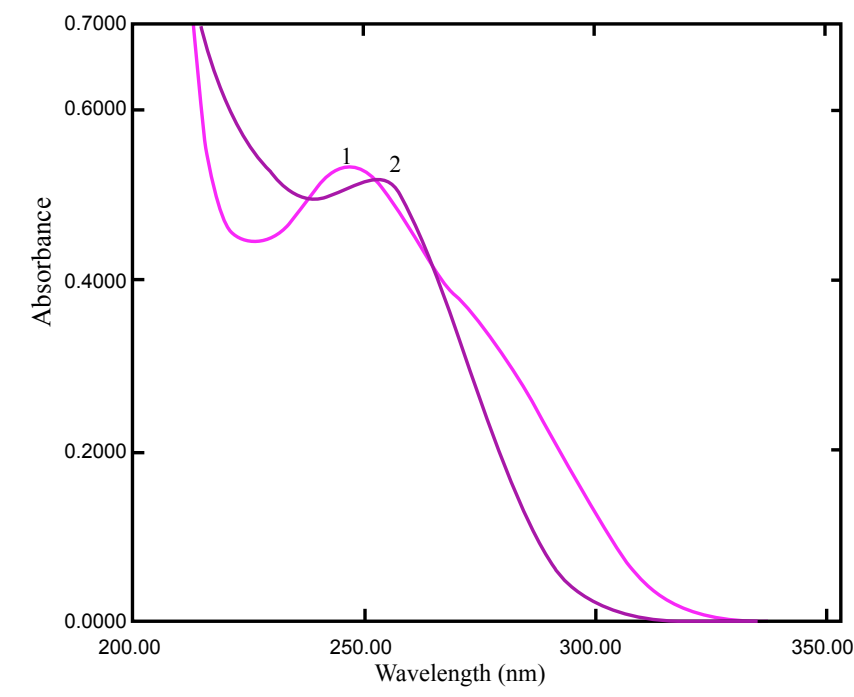

Figure 2: UV spectra of (1) atorvastatin and (2) celecoxib.

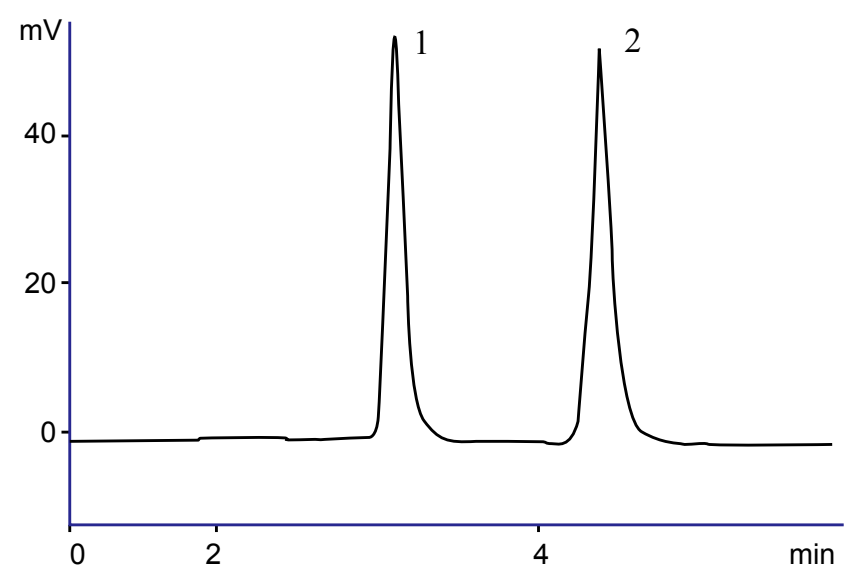

Figure 3: Representative chromatogram of atorvastatin ${ }^{1}$ and celecoxib ${ }^{2}$ at 250 $\mathrm{nm}$. 
Citation: Sultana N, Saeed Arayne M, Nadir Ali S, Tabassum A (2013) Simultaneous Liquid Chromatographic Determination of Two Co-Prescribed Anti-Cancer Drugs in Bulk Drug, Dosage Formulations and in Human Serum Using Multivariate Technique: Application to in vitro Drug Interaction. Pharmaceut Anal Acta 4: 215. doi:10.4172/2153-2435.1000215

Page 4 of 7

\begin{tabular}{|c|c|c|c|c|c|c|}
\hline $\begin{array}{c}\mathbf{n g} \\
\mathbf{m L}^{-1}\end{array}$ & $\mathbf{2 4 0} \mathbf{n m}$ & $\mathbf{2 4 5} \mathbf{n m}$ & $\mathbf{2 5 0} \mathbf{n m}$ & $\mathbf{2 5 5} \mathbf{~ n m}$ & $\mathbf{2 6 0} \mathbf{n m}$ & $\begin{array}{c}\text { Multi } \\
\text { Calibr }\end{array}$ \\
\hline \multicolumn{7}{|c|}{ Atorvastatin } \\
\hline 2 & 1.95 & 1.99 & 2.00 & 2.00 & 2.00 & 2.00 \\
\hline 4 & 3.93 & 3.99 & 4.00 & 4.01 & 3.98 & 4.02 \\
\hline 8 & 7.84 & 7.99 & 8.00 & 7.97 & 7.94 & 7.96 \\
\hline 16 & 15.16 & 14.88 & 14.71 & 15.33 & 14.77 & 15.95 \\
\hline 30 & 29.68 & 29.67 & 29.77 & 29.87 & 29.96 & 30.04 \\
\hline 60 & 58.82 & 59.59 & 60.00 & 59.19 & 59.41 & 59.98 \\
\hline \multicolumn{7}{|c|}{ Celecoxib } \\
\hline 2 & 2.01 & 2.00 & 1.99 & 2.01 & 2.00 & 2.00 \\
\hline 4 & 4.01 & 4.01 & 3.94 & 3.99 & 4.00 & 4.00 \\
\hline 8 & 8.03 & 8.00 & 8.06 & 7.98 & 8.00 & 16.01 \\
\hline 16 & 15.63 & 16.29 & 16.04 & 16.21 & 15.71 & 34.93 \\
\hline 35 & 35.21 & 35.15 & 35.04 & 35.61 & 35.05 & 50.29 \\
\hline 70 & 70.07 & 69.80 & 70.11 & 69.94 & 70.06 & 69.97 \\
\hline
\end{tabular}

Table 1: Accuracy of the method at different wavelengths.

\begin{tabular}{|c|c|c|c|c|c|}
\hline \multirow{2}{*}{$\begin{array}{c}\mathbf{n g} \\
\mathbf{m L}\end{array}$} & \multicolumn{5}{|c|}{$\mathbf{\%} \mathbf{~ R S D ~}$} \\
\cline { 2 - 6 } & $\mathbf{2 4 0} \mathbf{n m}$ & $\mathbf{2 4 5} \mathbf{~ n m}$ & $\mathbf{2 5 0} \mathbf{~ n m}$ & $\mathbf{2 5 5} \mathbf{~ n m}$ & $\mathbf{2 6 0} \mathbf{~ n m}$ \\
\hline \multicolumn{5}{|c|}{ Atorvastatin } \\
\hline 4 & 1.37 & 0.93 & 0.28 & 1.32 & 1.57 \\
\hline 8 & 0.21 & 0.58 & 1.19 & 0.11 & 0.17 \\
\hline 16 & 0.73 & 0.09 & 0.80 & 0.50 & 1.55 \\
\hline 30 & 1.51 & 0.10 & 1.02 & 1.11 & 1.55 \\
\hline 60 & 0.72 & 0.29 & 1.27 & 0.45 & 0.35 \\
\hline & 0.30 & 0.68 & 1.69 & 0.89 & 0.80 \\
\hline 2 & 0.59 & 0.92 & 2.20 & 0.35 & 0.60 \\
\hline 4 & 0.56 & 0.05 & 1.14 & 0.09 & 0.19 \\
\hline 8 & 0.36 & 0.20 & 0.09 & 0.24 & 0.29 \\
\hline 16 & 0.62 & 0.14 & 2.38 & 0.86 & 0.21 \\
\hline 35 & 1.41 & 0.27 & 1.36 & 0.10 & 0.21 \\
\hline 70 & 0.73 & 0.58 & 2.32 & 0.26 & 0.29 \\
\hline
\end{tabular}

Table 2: Precision of the method at different wavelengths.

\begin{tabular}{|c|c|c|c|c|c|c|}
\hline$\lambda_{\max }$ & Intercept & $\mathbf{R}^{2}$ & $\mathbf{S E}^{\mathrm{a}}$ & $\mathrm{SEE}^{\mathrm{b}}$ & $\begin{array}{c}\text { LOD } \\
\text { (ng mL-1) }\end{array}$ & $\begin{array}{c}\text { LOQ } \\
\left(\mathrm{ng} \mathrm{mL}^{-1}\right)\end{array}$ \\
\hline \multicolumn{7}{|c|}{ Atorvastatin } \\
\hline 240 & $Y=4958 x+23174$ & 0.9980 & 1.22 & 1.89 & 0.048 & 0.144 \\
\hline 245 & $Y=5020 x+23137$ & 0.9980 & 1.12 & 1.74 & 0.038 & 0.116 \\
\hline 250 & $Y=5102 x+23068$ & 0.9999 & 1.08 & 1.68 & 0.024 & 0.073 \\
\hline 255 & $Y=5057 x+23818$ & 0.9986 & 1.16 & 1.80 & 0.046 & 0.140 \\
\hline 260 & $Y=5052 x+22993$ & 0.9982 & 1.10 & 1.71 & 0.056 & 0.169 \\
\hline Serum & $Y=4692 x+52131$ & 0.9985 & 1.55 & 1.94 & 0.040 & 0.110 \\
\hline \multicolumn{7}{|c|}{ Celecoxib } \\
\hline 240 & $Y=4815 x+20851$ & 0.9980 & 0.96 & 1.32 & 0.050 & 0.153 \\
\hline 245 & $Y=4887 x+20996$ & 0.9985 & 0.73 & 1.00 & 0.031 & 0.093 \\
\hline 250 & $Y=4849 x+20827$ & 0.9982 & 0.83 & 1.14 & 0.019 & 0.057 \\
\hline 255 & $Y=4958 x+19862$ & 0.9985 & 0.73 & 1.01 & 0.010 & 0.030 \\
\hline 260 & $Y=4839 x+20380$ & 0.9980 & 1.01 & 1.40 & 0.049 & 0.149 \\
\hline Serum & $Y=4601 x+70072$ & 0.9979 & 0.50 & 0.33 & 0.010 & 0.030 \\
\hline
\end{tabular}

aStandard error, ${ }^{b}$ Standard error of estimate

Table 3: Regression characteristics.

\section{Method development and optimization}

The parameters were initially optimized; like mobile phase and $\mathrm{pH}$ were varied and preliminary tests were performed to establish the optimum conditions necessary for the analysis of drugs in pharmaceutical formulations and human serum. Separation was achieved on Bondapak, $\mathrm{C}_{18}(10 \mu \mathrm{m}, 25 \times 0.46 \mathrm{~cm})$ column. Different solvent system like acetonitrile-water and methanol-water in various ratios $(80: 20,70: 30,60: 40)$ were checked with varying $\mathrm{pH}(2.8-3.6)$ in order to study system suitability. Mobile phase 80:20 methanol-water with $\mathrm{pH}$ adjusted at 3.5 produced high resolution sharp peaks for both drug. The method was then applied for in vitro interaction studies of these drugs simulating human body environment. The $\%$ availability of drugs was calculated alone and in presence of each other. The proposed method is simple and does not involve much time to prepare samples.

\section{Method validation}

System suitability test: System suitability was evaluated by calculating the capacity factors $\left(k^{\prime}\right)$, theoretical plates $(\mathrm{N})$, tailing factor (T) and resolution (Rs). The column efficiency expressed by number of theoretical plates was greater than 2000 and tailing factor was in the range of 1.06-1.23. The data is summarized in table 4 .

Specificity: Specificity of developed method was demonstrated by injecting placebo like starch, magnesium stearate, lactose and hydroxymethylpropylcellulose individually under the same experimental conditions. Similarly the blank serum sample was injected to study the possible interference for the selectivity of atorvastatin and celecoxib. Both the tested samples were found to be free from interfering components or excipients at the retention times of analyte.

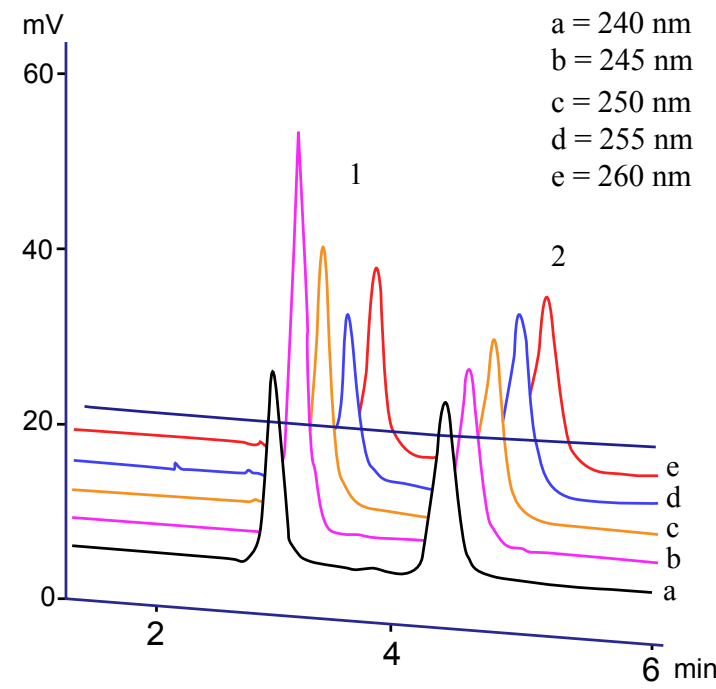

Figure 4: Analysis of atorvastatin ${ }^{1}$ and celecoxib ${ }^{2}$ at different wavelength

\begin{tabular}{|c|c|c|c|c|c|}
\hline Parameter & $\boldsymbol{\lambda}_{\max }$ & $\mathbf{k}^{\mathbf{a}}$ & $\mathbf{N}^{\mathbf{b}}$ & $\mathbf{T}^{\mathbf{c}}$ & $\mathbf{R e s}^{\mathbf{d}}$ \\
\hline Atorvastatin & 240 & 0.30 & 3827 & 1.18 & 0.76 \\
\hline & 245 & 0.70 & 3149 & 1.15 & 1.64 \\
\hline & 250 & 0.69 & 3147 & 1.15 & 1.78 \\
\hline & 255 & 0.68 & 3139 & 1.23 & 1.82 \\
\hline & 260 & 0.65 & 3137 & 1.23 & 1.87 \\
\hline Celecoxib & 240 & 0.82 & 3609 & 1.09 & 1.53 \\
\hline & 245 & 1.38 & 3351 & 1.06 & 1.48 \\
\hline & 250 & 1.37 & 3372 & 1.07 & 1.48 \\
\hline & 255 & 1.36 & 3405 & 1.06 & 1.48 \\
\hline & 260 & 1.30 & 3410 & 1.06 & 1.49 \\
\hline
\end{tabular}

${ }^{\mathrm{a} C}$ Capcity factor, ${ }^{\mathrm{b}}$ Thoeritical plates, ${ }^{\mathrm{C}}$ Tailing factor, ${ }^{\mathrm{d}}$ Resolution

Table 4: System suitability parameters. 
Citation: Sultana N, Saeed Arayne M, Nadir Ali S, Tabassum A (2013) Simultaneous Liquid Chromatographic Determination of Two Co-Prescribed Anti-Cancer Drugs in Bulk Drug, Dosage Formulations and in Human Serum Using Multivariate Technique: Application to in vitro Drug Interaction. Pharmaceut Anal Acta 4: 215. doi:10.4172/2153-2435.1000215

Representative chromatogram of solvent, reference standards, solution of pharmaceutical formulation and blank and spiked serum sample is shown in figure 5 .

Precision and repeatability: The precision of the method was assessed with respect to repeatability and is expressed in terms of relative standard deviation. The intraday precision (\%RSD) values obtained for repeatability studies at isobestic point of $250 \mathrm{~nm}$ were in the range of 0.13-1.90 for atorvastatin and celecoxib for API and human serum respectively. The data is presented in table 5 .

Accuracy: Accuracy of the proposed method was evaluated by performing the recovery tests of pharmaceutical formulation and human serum by spiking a known amount of standard solution followed by triplicate analysis using proposed method. The percent recovery values calculated were in the range of 99.33-101.65 and $99.20-101.44 \%$ in pharmaceutical formulations and human serum respectively (Table 5).

Linearity: Linearity of calibration graphs was found to be 2-60 and 2-70 $\mathrm{ng} \mathrm{mL}^{-1}$ for atorvastatin and celecoxib respectively. The correlation coefficient $\left(\mathrm{R}^{2}\right)$ obtained from regression line at each wavelength for bulk drug and human serum was greater than 0.998. Slope, intercept, standard error and standard error estimate are given in table 3.

Detection and quantization limits: The detection and quantization limits were calculated according to $\mathrm{ICH}$ guidelines using formulae: $\mathrm{LOD}=3.3 \mathrm{~S} / \mathrm{N}$ and $\mathrm{LOQ}=10 \mathrm{~S} / \mathrm{N}$, where $\mathrm{S}$ is the standard deviation of the peak area of the sample and $\mathrm{N}$ is the slope of calibration curve. At isobestic point, the LOD was found to be 0.024 and $0.019 \mathrm{ng} \mathrm{mL}^{-1}$ (in API) and 0.04 and $0.01 \mathrm{ng} \mathrm{mL}^{-1}$ (in serum) and LOQ was found to be 0.073 and $0.057 \mathrm{ng} \mathrm{mL}^{-1}$ (in API) and 0.11 and $0.03 \mathrm{ng} \mathrm{mL}^{-1}$ (in serum) for atorvastatin and celecoxib respectively (Table 3 ).

Ruggedness: In the ruggedness study, the operating parameters were deliberately changed and subsequent effect was examined. Under the same chromatographic conditions, one parameter was altered, while keeping others constant. It was observed that the proposed method is able to withstand relatively minor variations in parameters like $\mathrm{pH}$ and composition of mobile phase, flow rate etc (Table 6).

\section{In vitro interaction studies by RP-HPLC}

Patients with multiple number of medical complain are treated with a large number of medication, or most of the time more than one medicine is prescribed to patient for a single complain to accelerate the effect of each other. It may happen that these drugs interact with each other and suppress the potency of other leading to the increase or decrease in their bioavailability. It is therefore necessary to be aware of drug-drug interaction of simultaneously prescribed medicines in order to suggest the suitable drug therapy. Atorvastatin and celecoxib are two simultaneously prescribed anticancer drugs, also having potency to prevent the progression of atherosclerosis [27].

In the present study, the in vitro interaction of atorvastatin and celecoxib has been studied by RP-HPLC technique in buffers of $\mathrm{pH} 4$, 6.8 and 9 at physiological temperature simulating the $\mathrm{pH}$ of different areas of GI tract and blood $\mathrm{pH}$ and $\%$ availability was investigated in presence of each other. Prior to this, the availability of both the drugs were individually investigated under the same experimental conditions. Results of in vitro interaction studies of drugs at different $\mathrm{pH}$ is given in table 7 and representative chromatogram showing separation of atorvastatin and celecoxib after interaction at different $\mathrm{pH}$ is presented in figure 6. It was illustrated that up to $3 \mathrm{hrs}$, both drugs are available

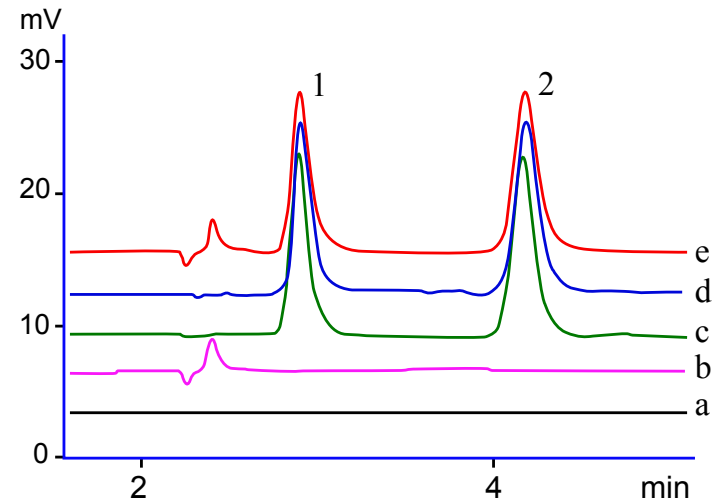

Figure 5: Representative chromatogram of (a) solvent, (b) blank serum, (c) standard solution of atorvastatin ${ }^{1}$ and celecoxib ${ }^{2}$ (d) dosage formulation solution and (e) serum sample spiked with standards at $250 \mathrm{~nm}$.

\begin{tabular}{|c|c|c|c|c|c|c|c|}
\hline \multirow{2}{*}{$\begin{array}{c}\mathbf{n g} \\
\mathbf{m L}^{-1}\end{array}$} & \%RSD & $\% \operatorname{Rec}$ & $\% \mathrm{Er}$ & \multirow{2}{*}{$\underset{\mathrm{mL}^{-1}}{\mathrm{ng}}$} & \multirow{2}{*}{$\begin{array}{c}\% \text { RSD } \\
\text { Cele }\end{array}$} & $\%$ Rec & $\% \mathrm{Er}$ \\
\hline & Ator & \multicolumn{2}{|c|}{ Genovax } & & & \multicolumn{2}{|c|}{ Celbexx } \\
\hline 2 & 0.28 & 100.34 & -0.34 & 2 & 0.58 & 101.65 & -1.65 \\
\hline 4 & 1.19 & 99.33 & 0.67 & 4 & 1.51 & 99.44 & 0.56 \\
\hline 8 & 0.80 & 99.90 & 0.10 & 8 & 0.29 & 101.47 & -1.47 \\
\hline 16 & 1.02 & 100.04 & -0.04 & 16 & 1.44 & 101.00 & -1.00 \\
\hline 30 & 1.27 & 99.85 & 0.15 & 35 & 0.74 & 99.99 & 0.01 \\
\hline 60 & 1.69 & 100.06 & -0.06 & 70 & 1.90 & 100.04 & -0.04 \\
\hline \multicolumn{8}{|c|}{ Serum } \\
\hline 4 & 0.15 & 100.11 & -0.11 & 4 & 0.43 & 101.15 & -1.76 \\
\hline 8 & 0.32 & 99.37 & 0.63 & 8 & 0.13 & 100.92 & -1.10 \\
\hline 16 & 1.39 & 99.20 & 0.80 & 16 & 0.27 & 101.44 & -1.06 \\
\hline
\end{tabular}

Table 5: Accuracy and precision of atorvastatin and celecoxib in pharmaceutical formulation and in human serum.

\begin{tabular}{|c|c|c|c|c|c|c|c|}
\hline \multirow{2}{*}{\multicolumn{2}{|c|}{ Parameter }} & \multicolumn{3}{|c|}{ Atorvastatin } & \multicolumn{3}{|c|}{ Celecoxib } \\
\hline & & \multirow{2}{*}{$\begin{array}{c}\mathbf{t}_{\mathrm{R}} \\
2.97\end{array}$} & \multirow{2}{*}{$\frac{\mathbf{N}}{4048}$} & \multirow{2}{*}{$\begin{array}{c}\mathbf{T} \\
1.51\end{array}$} & \multirow{2}{*}{$\begin{array}{c}\mathbf{t}_{\mathrm{R}} \\
3.96\end{array}$} & \multirow{2}{*}{$\begin{array}{c}\mathbf{N} \\
5148\end{array}$} & \multirow{2}{*}{$\begin{array}{c}\mathbf{T} \\
1.41\end{array}$} \\
\hline \multirow{3}{*}{$\mathrm{pH}$} & 3.4 & & & & & & \\
\hline & 3.5 & 3.08 & 3451 & 1.30 & 4.35 & 4235 & 1.16 \\
\hline & 3.6 & 3.15 & 4156 & 1.41 & 4.60 & 5272 & 1.26 \\
\hline \multirow{3}{*}{$\begin{array}{l}\text { Mobile } \\
\text { phase }\end{array}$} & $82: 18$ & 2.74 & 2914 & 1.47 & 3.68 & 3534 & 1.27 \\
\hline & $80: 20$ & 3.00 & 3115 & 1.46 & 4.03 & 3836 & 1.27 \\
\hline & $78: 22$ & 3.33 & 3300 & 1.53 & 4.46 & 4125 & 1.35 \\
\hline \multirow{3}{*}{$\begin{array}{l}\text { Flow } \\
\text { rate }\end{array}$} & 0.9 & 3.33 & 3341 & 1.52 & 4.47 & 4197 & 1.34 \\
\hline & 1.0 & 3.15 & 3615 & 1.44 & 4.17 & 4323 & 1.29 \\
\hline & 1.1 & 2.74 & 2908 & 1.48 & 3.68 & 3522 & 1.28 \\
\hline
\end{tabular}

Table 6: Ruggedness

\begin{tabular}{|c|c|c|c|c|c|c|c|}
\hline $\begin{array}{c}\text { Time } \\
(\mathbf{m i n})\end{array}$ & \multicolumn{2}{|c|}{ Atorvastatin } & Celecoxib & Atorvastatin & Celecoxib & Atorvastatin & Celecoxib \\
\hline 0 & 115.67 & 101.47 & 123.96 & 127.59 & 108.63 & 101.74 \\
\hline 30 & 98.42 & 98.00 & 99.07 & 98.85 & 99.78 & 99.04 \\
\hline 60 & 98.87 & 99.79 & 98.96 & 99.23 & 98.94 & 98.76 \\
\hline 90 & 98.38 & 100.64 & 99.58 & 98.80 & 99.36 & 98.42 \\
\hline 120 & 98.76 & 100.46 & 99.32 & 98.19 & 99.57 & 98.67 \\
\hline 150 & 98.52 & 100.38 & 99.10 & 98.84 & 98.36 & 98.12 \\
\hline 180 & 98.31 & 99.45 & 98.69 & 98.42 & 99.17 & 98.63 \\
\hline
\end{tabular}

Table 7: Interaction studies by RP-HPLC.

98-100\% at all the studied $\mathrm{pH}$ and no as such reduction in availability of drugs was observed indicating that no interaction occurred between atorvastatin and celecoxib. At the end of experiment, the availability 
Citation: Sultana N, Saeed Arayne M, Nadir Ali S, Tabassum A (2013) Simultaneous Liquid Chromatographic Determination of Two Co-Prescribed Anti-Cancer Drugs in Bulk Drug, Dosage Formulations and in Human Serum Using Multivariate Technique: Application to in vitro Drug Interaction. Pharmaceut Anal Acta 4: 215. doi:10.4172/2153-2435.1000215

Page 6 of 7

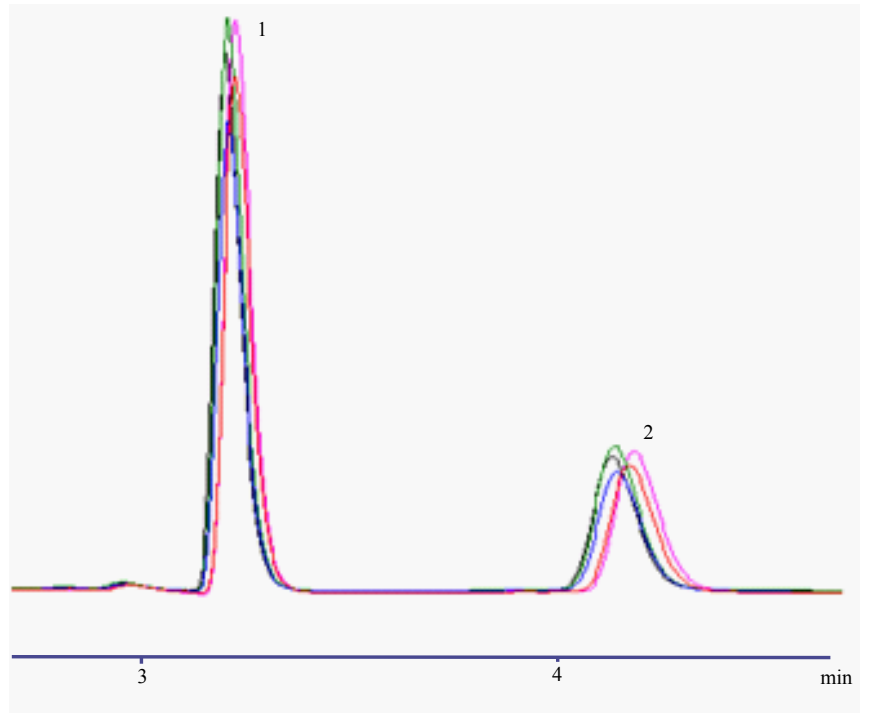

Figure 6: Chromatogram showing interaction of atorvastatin ${ }^{1}$ and celecoxib ${ }^{2}$.

of atorvastatin and celecoxib was $98.31,98.69$ and $99.17 \%$ and 99.45 98.42 and $98.63 \%$ at $\mathrm{pH} 4,6.8$ and 9 respectively.

\section{Conclusion}

In the present study, multivariate calibration technique based on regression analysis has been established for two widely co-prescribed anticancer drugs atorvastatin and celecoxib. This technique was subjected to high performance liquid chromatography for simultaneous quantitative analysis of binary mixtures with lowest detection limits.

It was found that the technique is fast, economic and involves non-destructive analytical measurements to estimate sample properties which would otherwise require time-consuming, expensive or destructive techniques. Good separation and resolution of the chromatographic peaks was achieved without interference of excipients and with good percent recoveries. All calibration curves were found to be linear with correlation coefficient greater than 0.997 . Moreover, the method showed excellent accuracy, precision, selectivity and reproducibility for simultaneous determination of both drugs in pharmaceutical formulations and in human serum. Also the in vitro interaction studies have been investigated for atorvastatin and celecoxib at $37^{\circ} \mathrm{C}$ in simulated stomach environment.

\section{Acknowledgement}

Financial support for this research work by Higher Education Commission, Pakistan is gratefully acknowledged by Scholar Saeeda Nadir Ali.

\section{References}

1. McCrindle BW, Ose L, Marais AD (2003) Efficacy and safety of atorvastatin in children and adolescents with familial hypercholesterolemia or severe hyperlipidemia: a multicenter, randomized, placebo-controlled trial. J Pediatr 143: $74-80$.

2. Nissen SE, Nicholls SJ, Sipahi I, Libby P, Raichlen JS, et al. (2006) Effect of very high-intensity statin therapy on regression of coronary atherosclerosis. JAMA 295: 1556-1565

3. Nawrocki JW, Weiss SR, Davidson MH, Sprecher DL, Schwartz SL, et al. (1995) Reduction of LDL cholesterol by $25 \%$ to $60 \%$ in patients with primary hypercholesterolemia by atorvastatin, a new HMG-CoA reductase inhibitor. Arterioscler Thromb Vasc Biol 15: 678-682.

4. Bakker-Arkema RG, Davidson MH, Goldstein RJ, Davignon J, Isaacsohn
JL, et al. (1996) Efficacy and safety of a new HMG-CoA reductase inhibitor, atorvastatin, in patients with hypertriglyceridemia. JAMA 275: 128-133.

5. Ozaki K, Kubo T, Imaki R, Shinagawa H, Fukaya H, et al. (2006) The antiatherosclerotic effects of lipid lowering with atorvastatin in patients with hypercholesterolemia. J Atheroscler Thromb 13: 216-219.

6. Schupp N, Schmid U, Heidland A, Stopper H (2008) Rosuvastatin protects against oxidative stress and DNA damage in vitro via upregulation of glutathione synthesis. Atherosclerosis 199: 278-287.

7. Sugiyama M, Ohashi M, Takase H, Sato K, Ueda R, et al. (2005) Effects of atorvastatin on inflammation and oxidative stress. Heart Vessels 20: 133-136.

8. Sassano A, Platanias LC (2008) Statins in tumor suppression. Cancer Lett 260: 11-19.

9. Weitz-Schmidt G (2002) Statins as anti-inflammatory agents. Trends Pharmacol Sci 23: 482-486.

10. Stalker TJ, Lefer AM, Scalia R (2001) A new HMG-CoA reductase inhibitor, rosuvastatin, exerts anti inflammatory effects on the microvascular endothelium the role of mevalonic acid. Br J Pharmacol 133: 406-412.

11. Resch U, Tatzber F, Budinsky A, Sinzinger H (2006) Reduction of oxidative stress and modulation of autoantibodies against modified low-density lipoprotein after rosuvastatin therapy. Br J Clin Pharmacol 61: 262-274.

12. Mach F (2002) Statins as immunomodulators. Transpl Immunol 9: 197-200.

13. Wong RP, Davis TM (2009) Statins as potential antimalarial drugs: low relative potency and lack of synergy with conventional antimalarial drugs. Antimicrob Agents Chemother 53: 2212-2214.

14. Garrett IR, Gutierrez G, Mundy GR (2001) Statins and bone formation. Curr Pharm Des 7: 715-736.

15. Shannon J, Tewoderos S, Garzotto M, Beer TM, Derenick R, et al. (2005) Statins and prostate cancer risk: a case-control study. Am J Epidemiol 162 318-325.

16. Moyad MA, Merrick GS, Butler WM, Wallner KE, Galbreath RW, et al. (2005) Statins, especially atorvastatin, may favorably influence clinical presentation and biochemical progression-free survival after brachytherapy for clinically localized prostate cancer. Urology 66: 1150-1154.

17. Bensen WG, Fiechtner JJ, McMillen JI, Zhao WW, Yu SS, et al. (1999) Treatment of osteoarthritis with celecoxib, a cyclooxygenase-2 inhibitor: a randomized controlled trial. Maya Clin Proc 74: 1095-1105.

18. Gnidec AG, Sibbald WJ, Cheung H, Metz CA (1988) Ibuprofen reduces the progression of permeability edema in an animal model of hyperdynamic sepsis. J Appl Physiol 65: 1024-1032.

19. Khoo NK, Chan FP, Saarloos MN, Lala PK (1992) Immunotherapy of mammary adenocarcinoma metastases in $\mathrm{C} 3 \mathrm{H} / \mathrm{HeN}$ mice with chronic administration of cyclo-oxygenase inhibitors alone or in combination with IL-2. Clin Exp Metastasis 10: 239-252.

20. Pruthi RS, Derksen JE, Moore D (2004) A pilot study of use of the cyclooxygenase- 2 inhibitor celecoxib in recurrent prostate cancer after definitive radiation therapy or radical prostatectomy. BJU Int 93: 275-278.

21. Xiao H, Yang CS (2008) Combination regimen with statins and NSAIDs: a promising strategy for cancer chemoprevention. Int J Cancer 123: 983-990.

22. Zheng X, Cui XX, Avila GE, Huang MT, Liu Y, et al. (2007) Atorvastatin and celecoxib inhibit prostate PC-3 tumors in immunodeficient mice. Clin Cancer Res 13: 5480-5487.

23. Reddy BS, Wang CX, Kong AN, Khor TO, Zheng X, et al. (2006) Prevention of azoxymethane-induced colon cancer by combination of low doses of atorvastatin, aspirin, and celecoxib in F 344 rats. Cancer Res 66: 4542-4546.

24. Swamy MV, Patlolla JM, Steele VE, Kopelovich L, Reddy BS, et al. (2006) Chemoprevention of familial adenomatous polyposis by low doses of atorvastatin and celecoxib given individually and in combination to APCM in mice. Cancer Res 66: 7370-7377.

25. Zheng X, Cui XX, Gao Z, Zhao Y, Lin Y, et al. (2010) Atorvastatin and celecoxib in combination inhibits progression of androgen-dependent LNCaP xenograft prostate tumors to androgen independence. Cancer Prev Res 3: 114-124. 
Citation: Sultana N, Saeed Arayne M, Nadir Ali S, Tabassum A (2013) Simultaneous Liquid Chromatographic Determination of Two Co-Prescribed Anti-Cancer Drugs in Bulk Drug, Dosage Formulations and in Human Serum Using Multivariate Technique: Application to in vitro Drug Interaction. Pharmaceut Anal Acta 4: 215. doi:10.4172/2153-2435.1000215

26. Zheng X, Cui XX, Gao Z, Zhao Y, Shi Y, et al. (2011) Inhibitory effect of dietary atorvastatin and celecoxib together with voluntary running wheel exercise on the progression of androgen-dependent LNCaP prostate tumors to androgen independence. Exp Ther Med 2: 221-228.

27. Raval M, Frank PG, Laury-Kleintop L, Yan G, Lanza-Jacoby S (2010) Celecoxib combined with atorvastatin prevents progression of atherosclerosis. J Surg Res 163: 113-122.

28. Sultana N, Arayne MS, Shah SN, Shafi N, Naveed S (2010) Simultaneous Determination of Prazosin, Atorvastatin, Rosuvastatin and Simvastatin in API, Dosage Formulations and Human Serum by RP-HPLC. Journal of the Chinese Chemical Society 57: 1286-1292.

29. Bahrami G, Mohammadi B, Mirzaeei S, Kiani A (2005) Determination of atorvastatin in human serum by reversed-phase high-performance liquid chromatography with UV detection. J Chromatogr B Analyt Tecnol Biomed Life Sci 826: 41-45.

30. Al-Rawithi S, Hussein RF, Alzahrani A (2003) Sensitive assay for the determination of fluvastatin in plasma utilizing high-performance liquid chromatography with fluorescence detection. Ther Drug Monit 25: 88-92.
31. Nirogi RV, Kandikere VN, Shukla M, Mudigonda K, Maurya S, et al. (2006) Simultaneous quantification of atorvastatin and active metabolites in human plasma by liquid chromatography-tandem mass spectrometry using rosuvastatin as internal standard. Biomed Chromatogr 20: 924-936.

32. Sultana N, Arayne MS, Naveed S (2011) Validated Method for the Simultaneous Determination of Lisinopril, Pravastatin, Atorvastatin and Rosuvastatin in API Formulations and Human Serum by RP HPLC. Chinese Journal of Chemistry 29: $1216-1220$.

33. Zarghi A, Shafaati A, Foroutan SM, Khoddam A (2006) Simple and rapid highperformance liquid chromatographic method for determination of celecoxib in plasma using UV detection: application in pharmacokinetic studies. J Chromatogr B Analyt Technol Biomed Life Sci 835: 100-104.

34. Bräutigam L, Vetter G, Tegeder I, Heinkele G, Geisslinger G (2001) Determination of celecoxib in human plasma and rat microdialysis samples by liquid chromatography tandem mass spectrometry. J Chromatogr B Biomed Sci Appl 761: 203-212

35. Rose MJ, Woolf EJ, Matuszewski BK (2000) Determination of celecoxib in human plasma by normal-phase high-performance liquid chromatography with column switching and ultraviolet absorbance detection. J Chromatogr B Biomed Sci Appl 738: 377-385. 